\title{
On the Structure of Palau'amine: Evidence for the Revised Relative Configuration from Chemical Synthesis
}

\author{
Brian A. Lanman ${ }^{\dagger}$, Larry E. Overman ${ }^{\star}$, Ralph Paulini, and Nicole S. White \\ Contribution from the Department of Chemistry, 1102 Natural Sciences II, University of California, \\ Irvine, California 92697-2025
}

\begin{abstract}
Hexacyclic congeners $\mathbf{2}$ and $\mathbf{3}$ of palau'amine, which incorporate both guanidine functional groups and have the cis configuration of the azabicyclo[3.3.0]octane core, are prepared in 14 steps from cycloadduct 6. Synthetic access to these analogs allows the first direct comparison of NMR data for hexacyclic diguanidine structures having the originally proposed cis-azabicyclo[3.3.0]octane fragment with data for natural alkaloids of the palau'amine family. This comparison provides convincing evidence in favor of the recently proposed structural revision of these marine alkaloids, fully supporting the trans configuration of the central azabicyclo[3.3.0]octane ring system of palau'amine and congeners.
\end{abstract}

\section{Introduction}

The stunning degree of structural diversity in the pyrrole-imidazole family of alkaloids provides an excellent example of biosynthetic efficiency. ${ }^{1}$ This large family of marine natural products is believed to be based on one simple metabolite, oroidin, and includes complex molecular architectures such as the hexacyclic oroidin dimer palau'amine (1, Figure 1) and alkaloids such as stylissadines A and B containing four oroidin subunits. Since its structural elucidation by mass spectral and NMR investigations in $1993,{ }^{2}$ palau' amine has received much attention from the synthetic community because of its promising immunomodulatory activity, challenging molecular architecture, and density of functionality. ${ }^{3}$ However, in spite of considerable efforts, no report of a successful total synthesis has emerged to date. ${ }^{1}$

Recently, the isolation and structural elucidation of additional palau'amine congeners has challenged the initial assignment of the relative configuration of palau'amine, leading to the proposal that stereogenic centers $\mathrm{C} 12$ and $\mathrm{C} 17$ should be inverted (2, Figure 1). ${ }^{4}$ Most notably, the revised structure $\mathbf{2}$ contains a highly strained trans-azabicyclo[3.3.0]octane fragment. Herein, we describe the synthesis of hexacyclic palau'amine derivatives 3 and $\mathbf{4}$ possessing the originally proposed cis-azabicyclo[ 3.3.0]octane central unit. Comparison of these compounds to palau'amine and tetrabromostyloguanidine $(\mathbf{5})^{4 c, 5}$ using NMR spectroscopic and computational methods provides additional evidence for the revised relative configuration 2 of palau'amine.

\section{Results and Discussion}

In our approach toward the putative original structure 1 of palau'amine, an intramolecular azomethine imine 1,3-dipolar cycloaddition forms the cis-azabicyclo[3.3.0]octane subunit

E-mail: leoverma@uci.edu.

${ }^{\dagger}$ Current address: Department of Medicinal Chemistry, Amgen, One Amgen Center Drive, Thousand Oaks, CA 91320-1799. 
having the correct relative configuration at the fully substituted carbons 10 and $16 .{ }^{6}$ Starting from this intermediate, elaboration to diguanidine hexacycles $3 / 4$ requires installation of the two spiroguanidine units and formation of the ketopiperazine ring. Building on precedent from Büchi's pioneering synthesis of dibromophakellin, ${ }^{7}$ ketopiperazine ring closure was projected to occur by attack of the nitrogen of a tethered bromopyrrole on a 2-methylsulfanyl- $4 \mathrm{H}$ -

imidazole generated in situ (Scheme 1). The second (right-hand) spirocycle was envisaged to arise in turn from an $S$-methyl thiohydantoin intermediate or by guanylation of the amino functional group of a suitable precursor, followed by spirocyclization.

An optimized synthetic route for the conversion of triazatriquinane 6 into hexacyclic palau'amine deriviatives $\mathbf{3} \mathbf{4}$, which have the same relative configuration at their stereogenic centers as the originally proposed structure $\mathbf{1}$ of palau' amine, is outlined in Scheme 2. This sequence began with $\mathrm{SmI}_{2}$-mediated reduction of the N-N bond of $\mathbf{6}$, followed by selective $\mathrm{S}$ methylation of the resulting thiohydantoin 7 to furnish the corresponding $S$-methyl isothiourea $\mathbf{8}(76 \%$ overall). Subsequent selective Teoc protection of the isothiourea provided intermediate 9 in quantitative yield. Many attempts to elaborate aminoester $\mathbf{9}$ into a hexacyclic diguanidine via the intermediacy of bis( $S$-methylthiohydantoin) spirocycles established the viability of the synthetic strategy for ketopiperazine ring closure, however, the diguanidine functional group array could not be formed from these intermediates. Alternative strategies involving delayed installation of the second spirocycle suffered from unproductive intramolecular rearrangements, originating from nucleophilic attack of the primary amine onto the adjacent isothiourea. Alternatively, direct guanylation of the $\alpha$-amino ester functionality of intermediates 8 and 9 to afford carbamate-protected glycocyamidine intermediates proved to be capricious and low-yielding. Therefore, a two-step procedure for glycocyamidine formation was developed, wherein aminoester 9 was first converted in high yield to Cbz-protected thiourea $\mathbf{1 0}$ by reaction with benzyloxycarbonyl isothiocyanate (11). ${ }^{8}$ Incubation of $\mathbf{1 0}$ with EDCI and $o$-nitrobenzylamine led to efficient installation of the protected guanidine functionality, presumably via the intermediacy of a carbamoylcarbodiimide, followed by in situ spirocyclization to afford glycocyamidine $\mathbf{1 2}$ in $93 \%$ overall yield. 9,10

Glycocyamidine 12 was elaborated to palau'amine derivatives $3 / 4$ in the following way. Chemoselective removal of the SEM protecting group in the presence of the secondary TBS ether was first accomplished by reaction of 12 with $10 \% \mathrm{TFA}-\mathrm{CH}_{2} \mathrm{Cl}_{2}$ at room temperature, followed by basic aqueous work-up to provide the free pyrrole 13. Reintroduction of the Teoc group furnished bromopyrrole bis(spirocycle) 14 in $85 \%$ overall yield. Reduction of the carbonyl groups of the spirocyclic fragments was achieved by exposure of bis(spirocycle) 14 to an excess of $\mathrm{NaBH}_{4}$ in $\mathrm{MeOH} / \mathrm{THF}$, providing a mixture of two inseparable bis(hemiaminal) diastereoisomers. In this transformation, the Teoc and $o$-nitrobenzyl groups impart sufficient electronic activation to the spirocycles to allow for smooth reduction of the carbonyl groups under mild conditions. The hemiaminal hydroxyl groups were then acetylated under standard conditions to give diastereomeric diacetates $\mathbf{1 5}$ and $\mathbf{1 6}$ in $80 \%$ combined yield and a ratio of 1.8:1. ${ }^{11}$ Although these diastereoisomers could be separated by standard chromatography, short exposure of either diastereoisomer, or the mixture, to TBAF/THF promoted cyclization to form the ketopiperazine ring to give an inseparable mixture of hemiaminal epimers 17 (ratio 1.5:1) in excellent yield (95\%). ${ }^{12,13}$ The configuration of the secondary alcohol was next inverted by a two-step sequence. Chemoselective oxidation of alcohol 17 with IBX provided ketone 18 in high yield (96\%) as an inseparable mixture of hemiaminal epimers (1.8:1). As expected, exposure of this ketone to $\mathrm{NaBH}_{4} / \mathrm{MeOH}$ resulted in hydride delivery from the convex face to give alcohol 19, again as an inseparable mixture of epimers $(1: 1,94 \%)$.

Treatment of this mixture with three equiv of purified $m$-chloroperoxybenzoic acid, ${ }^{14}$ followed by incubation of the sulfone products with ammonia provided diguanidine $\mathbf{2 0}$ in good overall yield (79\% after HPLC purification) as a 5:1 mixture of inseparable hemiaminal epimers. To complete the synthesis of $\mathbf{3}$ and $\mathbf{4}$, the $o$-nitrobenzyl and $\mathrm{Cbz}$ protecting groups were cleaved 
by photolysis and hydrogenolysis, respectively. In the course of the latter reaction, the bromine substituents of the pyrrole were also removed to provide a 2:1 mixture of hemiaminal epimers 3 and 4 in 65\% combined overall yield. Although this mixture of hemiaminal epimers could be separated by HPLC, interconversion of the two diastereoisomers in $\mathrm{H}_{2} \mathrm{O} / \mathrm{MeCN} / \mathrm{TFA}$ (89:11:0.1) and $\mathrm{D}_{2} \mathrm{O}$ thwarted their isolation as single stereoisomers.

Gratifyingly, most of the NMR resonances of diastereoisomers 3 and $\mathbf{4}$ in $\mathrm{D}_{2} \mathrm{O}$ were well separated and allowed for full assignment of ${ }^{1} \mathrm{H}$ and ${ }^{13} \mathrm{C}$ NMR spectra (Table 1). Comparison of ${ }^{1} \mathrm{H}$ and ${ }^{13} \mathrm{C}$ chemical shifts of $\mathbf{3}$ and $\mathbf{4}$ with those published for palau' amine ${ }^{2 b}$ reveals a surprisingly close overall match considering the dissimilarities in substituents at $\mathrm{C} 17$ and $\mathrm{C} 18$. An important difference, however, is the value of the ${ }^{1} \mathrm{H},{ }^{1} \mathrm{H}$ coupling constant for the angular protons of the azabicyclo[3.3.0]octane moiety, which are 12.0 and $10.7 \mathrm{~Hz}$ for $\mathbf{3}$ and $\mathbf{4}$, respectively. This vicinal coupling constant is greater than $14 \mathrm{~Hz}$ for palau'amine and all palau' amine congeners, with the large value of this coupling constant for the natural alkaloids being an important piece of evidence in support of the revised trans fusion of the azabicyclo [3.3.0] octane unit. ${ }^{4 \mathrm{c}}$ In addition, qualitative interpretation of the NOESY spectra of $\mathbf{3}$ and $\mathbf{4}$ revealed a strong correlation between the two protons at the ring junction $(\mathrm{H} 11 / \mathrm{H} 12)$, and the absence or weak correlations for the 1,3-related pairs of protons $\mathrm{H} 11 / \mathrm{H} 18$ and $\mathrm{H} 11 / \mathrm{H} 13 \beta$, respectively. This latter data again stands in sharp contrast to data published for palau'amine and its congeners, in which a NOE correlation between $\mathrm{H} 11$ and $\mathrm{H} 12$ was often not mentioned, $\left.{ }^{15}\right]$ and correlations for $\mathrm{H} 11 / \mathrm{H} 13 \beta$ and $\mathrm{H} 11 / \mathrm{H} 18$ were reported. As an additional point of divergence, correlations between $\mathrm{H} 13 \alpha$ and $\mathrm{H} 18$ were observed for $\mathbf{3}$ and $\mathbf{4}$, whereas $\mathrm{H} 18$ was correlated to H13 $\beta$ in the natural products. No correlation between $\mathrm{H} 13 \beta$ and $\mathrm{H} 18$ was observed for 3 or 4.

For further corroboration of the qualitative interpretation of NOE correlations, a quantitative NOESY analysis was carried out to experimentally determine important interproton distances. 16 Data gathered from these experiments were evaluated by comparison to the corresponding distances obtained from in silico geometry optimization, and to values published for tetrabromostyloguanidine (5). ${ }^{4 \mathrm{c}}$ Geometry optimizations performed using the molecular modeling packages Maestro 5.0.019 with the AMBER* forcefield including solvation $\left(\mathrm{H}_{2} \mathrm{O}\right)$ and Spartan 04 (B3LYP 6-31G*) returned consistent results. ${ }^{17}$

A selected set of diagnostic interproton distances obtained from NOESY experiments and the corresponding calculated values are given in Table 2 (for further details see the Supporting Information).

Overall, experimentally determined interproton distances were in good agreement with results obtained from molecular modeling. The similar distances between $\mathrm{H} 11$ and $\mathrm{H} 20$ for $\mathbf{3}$ and tetrabromostyloguanidine (5) (270 and $271 \mathrm{pm}$ ) and the respective shorter distance seen in hemiaminal epimer $4(208 \mathrm{pm})$, support a relative configuration at C20 of palau' amine identical to that of analog 3 and tetrabromostyloguanidine (5). As expected for the cis-fusion of the fivemembered rings, short distances were obtained between the angular protons $\mathrm{H} 11$ and H12 (221 and $228 \mathrm{pm}$ for $\mathbf{3}$ and $\mathbf{4}$, respectively). The corresponding distance in the trans-fused ring system, which is predicted by molecular modeling to be considerably larger (304 pm), unfortunately could not be quantified in the investigation of tetrabromostyloguanidine (5). ${ }^{4 \mathrm{c}}$ More diagnostic information was obtained from the examination of 1,3-interrelated proton pairs $\mathrm{H} 11 / \mathrm{H} 13 \beta, \mathrm{H} 11 / \mathrm{H} 18$, and $\mathrm{H} 13 \beta / 18$, situated on the same side of the molecular plane. In accordance with the molecular model of cis-configured structure $\mathbf{1}$, all of these distances were found to be large ( $\geq 334 \mathrm{pm}$ ) for $\mathbf{3}$ and $\mathbf{4}$, whereas significantly shorter interproton distances $(\leq 260 \mathrm{pm})$ were reported for tetrabromostyloguanidine (5), and calculated for $\mathbf{2}$ and hypothetical trans-configured diastereoisomers trans-3 and trans-4. In particular, the distance between $\mathrm{H} 11$ and $\mathrm{H} 13 \beta$, which could be experimentally quantified in all cases, was found to 
be $85 \mathrm{pm}$ larger for cis-fused $\mathbf{3}$ and $\mathbf{4}(335$ and $334 \mathrm{pm})$ than for tetrabromostyloguanidine (5) $(250 \mathrm{pm})$. No NOE correlations were observed for proton pairs H11/H18 and H13 $\beta / 18$ in the case of $\mathbf{3}$ and $\mathbf{4}$, whereas the corresponding distances for $\mathbf{5}$ were experimentally determined to be short ( 233 and $266 \mathrm{pm}$, respectively). In addition, the close proximity of H12 and H18 ( 249 and $227 \mathrm{pm}$ ) and a NOE correlation between H13 $\alpha$ and H18 (313 and 292 pm), observed in the case of $\mathbf{3}$ and $\mathbf{4}$, were not mentioned in the quantitative analysis of tetrabromostyloguanidine (5). As highlighted by Grube and Köck, ${ }^{4 \mathrm{c}}$ this discrepancy is best explained by assuming a trans fusion of the central azabicyclic fragment of palau'amine and congeners.

\section{Conclusions}

In summary, the first synthesis of hexacyclic palau'amine congeners that incorporate both guanidine functional groups has been accomplished. These palau' amine analogs, $\mathbf{3}$ and $\mathbf{4}$, have the cis configuration of their azabicyclo[3.3.0]octane cores. Synthetic access to these analogs allowed the first direct comparison of NMR data for hexacyclic diguanidine structures having the originally proposed cis-azabicyclo[ 3.3.0]octane fragment with data for natural alkaloids of the palau'amine family. This comparison provides additional strong evidence in favor of the recently proposed structural revision of these compounds, fully supporting the trans configuration of the central azabicyclo[3.3.0]octane ring system of palau' amine and congeners.

\section{Experimental Section 18}

\section{Intermediate 17}

$n$-Tetrabutylammonium fluoride ( $155 \mu \mathrm{L}$ of a 1 м solution in THF, $0.155 \mathrm{mmol}$ ) was added at room temperature to a solution of bis(spirocycle) 15 (37 mg, $0.031 \mathrm{mmol})$ in THF $(2 \mathrm{~mL})$, and the yellowish solution was stirred at room temperature for $8 \mathrm{~min}$., then partitioned between saturated aqueous $\mathrm{NH}_{4} \mathrm{Cl}$ solution and EtOAc. The organic phase was dried over $\mathrm{Na}_{2} \mathrm{SO}_{4}$ and concentrated. The residue was purified by column chromatography $\left(\mathrm{SiO}_{2} ; \mathrm{EtOAc} / \mathrm{MeOH} 14: 1\right)$ to afford $24.5 \mathrm{mg}(95 \%)$ of an inseparable mixture (1.5:1) of hemiaminal diastereoisomers 17 as a colorless, amorphous solid. ${ }^{1} \mathrm{H}$ NMR $\left(500 \mathrm{MHz}, \mathrm{CD}_{3} \mathrm{OD}\right) \delta 8.04(\mathrm{~d}, J=7.9 \mathrm{~Hz}, 1 \mathrm{H})$, $7.90(\mathrm{~d}, J=7.8 \mathrm{~Hz}, 0.66 \mathrm{H}), 7.66(\mathrm{t}, J=7.9 \mathrm{~Hz}, 1 \mathrm{H}), 7.53-7.45(\mathrm{~m}, 3.98 \mathrm{H}), 7.36-7.23(\mathrm{~m}, 8.3$ $\mathrm{H}), 6.95(\mathrm{~s}, 0.66 \mathrm{H}), 6.94(\mathrm{~s}, 1 \mathrm{H}), 6.22(\mathrm{~s}, 1 \mathrm{H}), 5.81(\mathrm{~s}, 0.66 \mathrm{H}), 5.06-5.01(\mathrm{~m}, 5.64 \mathrm{H}), 4.78$ $(\mathrm{d}, J=17.4 \mathrm{~Hz}, 1 \mathrm{H}), 4.63(\mathrm{~m}, 1.66 \mathrm{H}), 4.44-4.37(\mathrm{~m}, 2.66 \mathrm{H}), 3.46(\mathrm{~m}, 1.66 \mathrm{H}), 3.37(\mathrm{~m}, 0.66$ $\mathrm{H}), 2.75-2.59(\mathrm{~m}, 3.32 \mathrm{H}), 2.52-2.45(\mathrm{~m}, 5.64 \mathrm{H}), 2.02(\mathrm{bd}, J=10.3 \mathrm{~Hz}, 1 \mathrm{H}) ;{ }^{13} \mathrm{C}$ NMR $(125$ $\left.\mathrm{MHz}, \mathrm{CD}_{3} \mathrm{OD}\right) \delta 169.9,149.4,165.3,165.2,163.7,162.8,155.3,150.3,149.9,138.8,138.6$, $134.8,134.5,134.2,133.5,131.8,130.4,130.0,129.61,129.59,129.5,129.14,129.07,129.0$, $126.2,126.1,124.7,124.4,117.3,117.2,109.3,109.0,93.0,92.5,89.3,88.5,76.8,76.5,71.8$, 70.5, 69.9, 68.5, 68.3, 60.4, 56.1, 50.7, 50.4, 44.1, 43.3, 40.8, 30.9, 14.6, 13.9; FTIR (film) $3371,3263,2933,1636,1590,1524,1497,1443,1426,1383,1337,1287,1266,1119,1063$, $982,799,735,700 \mathrm{~cm}^{-1}$; HRMS (ESI) $\mathrm{m} / z$ calcd. for $\mathrm{C}_{32} \mathrm{H}_{30} \mathrm{Br}_{2} \mathrm{~N}_{8} \mathrm{NaO}_{7} \mathrm{~S}(\mathrm{M}+\mathrm{Na}): 851.0223$, found: 851.0219 .

\section{Intermediate 20}

A solution of $m$-chloroperoxybenzoic acid (washed with saturated aqueous $\mathrm{NaHCO}_{3}$ solution; $5.4 \mathrm{mg}, 0.031 \mathrm{mmol})$ in $\mathrm{CH}_{2} \mathrm{Cl}_{2}(1 \mathrm{~mL})$ was added at $0{ }^{\circ} \mathrm{C}$ to a solution of hemiaminal diastereoisomers 19 ( $8.6 \mathrm{mg}, 0.01 \mathrm{mmol})$ in $\mathrm{CH}_{2} \mathrm{Cl}_{2}(2 \mathrm{~mL})$ in a sealable high-pressure reaction tube. The resulting clear solution was stirred at $0{ }^{\circ} \mathrm{C}$ for $10 \mathrm{~min}$., then allowed to warm to room temperature and stirred for another $30 \mathrm{~min}$. This solution was cooled to $-78^{\circ} \mathrm{C}$, and $\mathrm{NH}_{3}$ (ca. $3 \mathrm{~mL}$ ) was condensed into the solution. The reaction tube was sealed, and the resulting cloudy solution was allowed to warm to room temperature (clear solution after ca. $10 \mathrm{~min}$ ), and kept at this temperature for $14 \mathrm{~h}$. The solution was then re-cooled to $-78^{\circ} \mathrm{C}$, the tube was unsealed, 
and excess $\mathrm{NH}_{3}$ was allowed to evaporate with warming to room temperature. The resulting suspension was concentrated, and the residue was purified by RP-HPLC (Phenomenex C18, $5 \mu \mathrm{m}, 250 \times 21.2 \mathrm{~mm}, \mathrm{H}_{2} \mathrm{O}$ (with 0.1\% TFA) $/ \mathrm{MeOH}$ linear gradient 50:50 $\rightarrow$ 10:90 in 20 $\mathrm{min}$, flow rate $\left.10 \mathrm{~mL} / \mathrm{min}, \mathrm{t}_{\mathrm{R}}=14.8 \mathrm{~min}\right)$ to provide $7.5 \mathrm{mg}(79 \%)$ of an inseparable mixture (5:1) of bis(guanidine) diastereoisomers $\mathbf{2 0}$ (as the trifluoroacetate salts) as a colorless, glasslike solid. ${ }^{1} \mathrm{H}$ NMR (500 MHz, $\left.\mathrm{CD}_{3} \mathrm{OD}\right) \delta 8.17(\mathrm{~d}, J=8.1 \mathrm{~Hz}, 1 \mathrm{H}), 8.09(\mathrm{~d}, J=8.1 \mathrm{~Hz}, 0.2$ H), $7.78(\mathrm{t}, J=7.6 \mathrm{~Hz}, 1 \mathrm{H}), 7.71(\mathrm{t}, J=7.7 \mathrm{~Hz}, 0.2 \mathrm{H}), 7.61(\mathrm{t}, J=7.7 \mathrm{~Hz}, 1.2 \mathrm{H}), 7.55(\mathrm{~d}, J$ = 7.7 Hz, 1 H), 7.41-7.31 (m, 6.2 H), $7.07(\mathrm{~s}, 0.2 \mathrm{H}), 7.06(\mathrm{~s}, 1 \mathrm{H}), 6.57(\mathrm{~s}, 1 \mathrm{H}), 6.25(\mathrm{~s}, 0.2$ H), $5.31(\mathrm{~d}, J=17.4 \mathrm{~Hz}, 1 \mathrm{H}), 5.29(\mathrm{~d}, J=12.2 \mathrm{~Hz}, 0.2 \mathrm{H}), 5.26(\mathrm{~d}, J=12.2 \mathrm{~Hz}, 0.2 \mathrm{H}), 5.23$ $(\mathrm{s}, 2 \mathrm{H}), 4.97(\mathrm{~d}, J=17.4 \mathrm{~Hz}, 1 \mathrm{H}), 4.84(\mathrm{~d}, J=16.6 \mathrm{~Hz}, 0.2 \mathrm{H}), 4.31(\mathrm{~m}, 1.2 \mathrm{H}), 4.24(\mathrm{dd}, J$ $=9.9,12.4 \mathrm{~Hz}, 1 \mathrm{H}), 4.05(\mathrm{dd}, J=8.9,12.4 \mathrm{~Hz}, 0.2 \mathrm{H}), 3.86(\mathrm{~d}, J=12.2 \mathrm{~Hz}, 1 \mathrm{H}), 3.77$ (dd, $J=3.8,12.4 \mathrm{~Hz}, 0.2 \mathrm{H}), 3.67(\mathrm{dd}, J=6.5,12.4 \mathrm{~Hz}, 1 \mathrm{H}), 3.11(\mathrm{dd}, J=6.4,15.5 \mathrm{~Hz}, 0.2 \mathrm{H})$, $3.04(\mathrm{~m}, 1.2 \mathrm{H}), 2.32(\mathrm{~d}, J=13.8 \mathrm{~Hz}, 1 \mathrm{H}), 2.28(\mathrm{~d}, J=13.8 \mathrm{~Hz}, 1 \mathrm{H}), 2.16(\mathrm{dd}, J=3.1,15.5$ $\mathrm{Hz}, 0.2 \mathrm{H}) ;{ }^{13} \mathrm{C}$ NMR $\left(125 \mathrm{MHz}, \mathrm{CD}_{3} \mathrm{OD}\right) \delta 158.95,158.93,158.88,158.6,155.8,155.4$, $150.1,149.7,137.1,136.9,135.4,135.3,134.0,132.2,132.1,131.4,131.3,130.9,130.7,130.5$, $130.3,129.8,129.6,129.4,129.2,126.8,126.7,124.7,124.5,118.6,118.2,109.3,109.0,104.9$, $104.5,90.8,89.3,83.5,83.2,72.2,71.8,70.4,70.1,70.0,69.9,69.4,69.0,54.8,52.8,47.2$, 45.4, 45.1, 44.8, 44.1, 43.0, 42.5; FTIR (film) 2244, 3261, 2916, 2873, 2831, 1766, 1702, 1671, 1594, 1528, 1439, 1345, 1272, 1202, 1135, 801, $724 \mathrm{~cm}^{-1}$; HRMS (ESI) $\mathrm{m} / \mathrm{z}$ calcd. for $\mathrm{C}_{31} \mathrm{H}_{29} \mathrm{Br}_{2} \mathrm{~N}_{9} \mathrm{O}_{7}(\mathrm{M}+\mathrm{H})$ : 798.0635, found: 798.0668.

\section{Products 3 and 4}

A solution of bis(guanidine) diastereoisomers $20(25 \mathrm{mg}, 0.027 \mathrm{mmol})$ in dioxane $(5 \mathrm{~mL})$ was irradiated at room temperature for $2.5 \mathrm{~h}$ using a sunlamp $(275 \mathrm{~W}) . \mathrm{Pd} / \mathrm{C}(10 \%, 10 \mathrm{mg}) \mathrm{was}$ added to the resulting yellow solution, and the suspension was stirred under a $\mathrm{H}_{2}$ atmosphere for $4 \mathrm{~h}$. The suspension was filtered through Celite, and the Celite was washed with dioxane $(1 \mathrm{~mL})$ and $\mathrm{H}_{2} \mathrm{O} / 0.1 \%$ TFA $(1 \mathrm{~mL}) . \mathrm{Pd} / \mathrm{C}(10 \%, 20 \mathrm{mg})$ was added to the yellowish filtrate, and the suspension was stirred under a $\mathrm{H}_{2}$ atmosphere for $24 \mathrm{~h}$, then filtered $(45 \mu \mathrm{m}$ nylon filter). The filtrate was concentrated, and the residue was redissolved in $\mathrm{H}_{2} \mathrm{O} / 0.1 \% \mathrm{TFA}$ and purified by RP-HPLC (Phenomenex C18, $5 \mu \mathrm{m}, 250 \times 21.2 \mathrm{~mm}, \mathrm{H}_{2} \mathrm{O}$ (with $0.1 \%$ TFA) / $\mathrm{CH}_{3} \mathrm{CN}$ linear gradient $95: 5 \rightarrow 80: 20$ in $20 \mathrm{~min}$, flow rate $10 \mathrm{~mL} / \mathrm{min}$ ) to afford $8 \mathrm{mg}(43 \%)$ and $4.1 \mathrm{mg}(22 \%)$ of bis(guanidine) hemiaminal diastereoisomers 3 and $\mathbf{4}$ respectively, (enriched, as the bis(trifluoroacetate) salts), as colorless, glass-like solids. ${ }^{19}$ Data for 3: $\mathrm{t}_{\mathrm{R}}=$ $14.9 \mathrm{~min} ;{ }^{1} \mathrm{H} \mathrm{NMR}\left(500 \mathrm{MHz}, \mathrm{D}_{2} \mathrm{O}\right) \delta 7.13(\mathrm{~d}, J=1.3,2.7 \mathrm{~Hz}, 1 \mathrm{H}), 6.97$ (dd, $J=1.3,4.0 \mathrm{~Hz}$, $1 \mathrm{H}), 6.47(\mathrm{dd}, J=2.7,4.0 \mathrm{~Hz}, 1 \mathrm{H}), 6.36(\mathrm{~s}, 1 \mathrm{H}), 5.34(\mathrm{~s}, 1 \mathrm{H}), 4.34(\mathrm{~m}, 1 \mathrm{H}), 4.16(\mathrm{dd}, J=$ $10.1,12.3 \mathrm{~Hz}, 1 \mathrm{H}), 3.82(\mathrm{~d}, J=12.0 \mathrm{~Hz}, 1 \mathrm{H}), 3.65$ (dd, $J=6.1,12.3 \mathrm{~Hz}, 1 \mathrm{H}), 3.07$ (m, $1 \mathrm{H})$, $2.35(\mathrm{dd}, J=3.7,14.3 \mathrm{~Hz}, 1 \mathrm{H}), 2.16(\mathrm{~d}, J=14.3 \mathrm{~Hz}, 1 \mathrm{H}) ;{ }^{13} \mathrm{C} \mathrm{NMR}\left(125 \mathrm{MHz}, \mathrm{D}_{2} \mathrm{O}\right) \delta 158.7$, 157.4, 156.9, 124.7, 120.5, 115.0, 113.0, 85.8, 82.0, 71.9, 70.1, 68.1, 53.1, 49.9, 45.3, 42.2; FTIR (film) 3188, 2836, 1671, 1578, 1557, 1472, 1432, 1389, 1326, 1191, 1135, 1092, 1038, 843, 801, $724 \mathrm{~cm}^{-1}$; HRMS (ESI) $\mathrm{m} / z$ calcd. for $\mathrm{C}_{16} \mathrm{H}_{20} \mathrm{~N}_{8} \mathrm{O}_{3}(\mathrm{M}+\mathrm{H}): 373.1737$, found: 373.1736. Data for 4: $\mathrm{t}_{\mathrm{R}}=13.9 \mathrm{~min} ;{ }^{1} \mathrm{H}$ NMR $\left(500 \mathrm{MHz}, \mathrm{D}_{2} \mathrm{O}\right) \delta 7.10(\mathrm{~d}, J=1.3,2.7 \mathrm{~Hz}, 1$ H), $6.97(\mathrm{dd}, J=1.3,4.0 \mathrm{~Hz}, 1 \mathrm{H}), 6.47(\mathrm{dd}, J=2.7,4.0 \mathrm{~Hz}, 1 \mathrm{H}), 6.24(\mathrm{~s}, 1 \mathrm{H}), 5.19(\mathrm{~s}, 1 \mathrm{H})$, $4.34(\mathrm{~m}, 1 \mathrm{H}), 4.07(\mathrm{dd}, J=9.9,12.3 \mathrm{~Hz}, 1 \mathrm{H}), 3.72(\mathrm{dd}, J=4.6,12.3 \mathrm{~Hz}, 1 \mathrm{H}), 3.35(\mathrm{~d}, J=$ $10.7 \mathrm{~Hz}, 1 \mathrm{H}), 3.15(\mathrm{~m}, 1 \mathrm{H}), 2.79$ (dd, $J=5.1,15.4 \mathrm{~Hz}, 1 \mathrm{H}), 2.08$ (dd, $J=2.5,15.4 \mathrm{~Hz}, 1$ $\mathrm{H}) ;{ }^{13} \mathrm{C}$ NMR $\left(125 \mathrm{MHz}, \mathrm{D}_{2} \mathrm{O}\right) \delta 158.7,157.4,156.7,124.5,120.3,115.0,113.2,87.9,81.8$, 70.7, 69.2, 68.7, 59.9, 44.2, 42.7, 41.2.

\section{Supplementary Material}

Refer to Web version on PubMed Central for supplementary material. 


\section{Acknowledgment}

Financial support from the National Heart, Lung, and Blood Institute (HL-25854), NIH NRSA postdoctoral fellowship support to B.A.L. (GM-71132), and Deutsche Akademie der Naturforscher Leopoldina (BMBF-LPD 9901/8-142) postdoctoral fellowship support for R.P. are gratefully acknowledged. We thank Prof. J.S. Nowick for helpful discussions.

\section{References}

1. For recent reviews on the structural diversity of pyrrole-imidazole alkaloids and synthetic approaches toward some of the family members, see: (a) Hoffmann H, Lindel T. Synthesis 2003:1753-1783. (b) Jacquot DEN, Lindel T. Curr. Org. Chem 2005;9:1551-1565.

2. (a) Kinnel RB, Gehrken H-P, Scheuer PJ. J. Am. Chem. Soc 1993;115:3376-3377. (b) Kinnel RB, Gehrken H-P, Swali R, Skoropowski G, Scheuer PJ. J. Org. Chem 1998;63:3281-3286.. Additional congeners have been isolated and characterized: (c) Kato T, Shizuri Y, Izumida H, Yokoyama A, Endo M. Tetrahedron Lett 1995;36:2133-2136. (d) Kobayashi J, Suzuki M, Tsuda M. Tetrahedron 1997;53:15681-15684.

3. Publications not covered in Refs. 1a and 1b include: (a) Dransfield PJ, Dilley AS, Wang S, Romo D. Tetrahedron 2006;62:5223-5247. (b) Wang S, Dilley AS, Poullennec KG, Romo D. Tetrahedron 2006;62:7155-7161. (c) Nakadai M, Harran PG. Tetrahedron Lett 2006;47:3933-3935. (d) Tan X, Chen C. Angew. Chem. Int. Ed 2006;45:4345-4348.

4. (a) Kobayashi H, Kitamura K, Nagai K, Nakao Y, Fusetani N, van Soest RWM, Matsunaga S. Tetrahedron Lett 2007;48:2127-2129. (b) Buchanan MS, Carroll AR, Addepalli R, Avery VM, Hooper JNA, Quinn RJ. J. Org. Chem 2007;72:2309-2317. [PubMed: 17315930] (c) Grube A, Köck M. Angew. Chem. Int. Ed 2007;46:2320-2324.. The relative configuration of the C20 stereogenic center was assigned as shown for $\mathbf{1}$ in the initial isolation report (Ref. 2a), then corrected in the following publication (Ref. 2b). All congeners of palau' amine were assigned the initial relative configuration at C20 (Refs. 2c, 2d, 4a-c).

5. This natural product was also isolated from another marine sponge and named carteramine A, see Ref. 4a.

6. (a) Overman LE, Rogers BN, Tellew JE, Trenkle WC. J. Am. Chem. Soc 1997;119:7159-7160. (b) Bélanger G, Hong F-T, Overman LE, Rogers BN, Tellew JE, Trenkle WC. J. Org. Chem 2002;67:7880-7883. [PubMed: 12398520] (c) Katz JD, Overman LE. Tetrahedron 2004;60:9559_ 9568.

7. Foley LH, Büchi G. J. Am. Chem. Soc 1982;104:1776-1777.

8. Prepared from potassium thiocyanate and benzyl chloroformate according to: WangSSMaglioccoLGAmerican Cyanamid CompanyUS Patent51946731993(see the Supporting Information)

9. Treatment of $\mathbf{1 0}$ with EDCI and an excess of hexamethyldisilazane (HMDS) under similar conditions provided the corresponding (monoprotected) guanidine, which could be converted to the glycocyamidine spirocycle by incubation with diisopropylethylamine in toluene at $80{ }^{\circ} \mathrm{C}$ for $6 \mathrm{~h}$ (see Ref. 10d). However, carbamate protection of the endocyclic glycocyamidine nitrogen provided derivatives that were labile, and, therefore, inferior to intermediates masked with alkyl groups.

10. (a) Linton BR, Carr AJ, Orner BP, Hamilton AD. J. Org. Chem 2000;65:1566-1568. [PubMed: 10814126] (b) Manimala JC, Anslyn EV. Tetrahedron Lett 2002;43:565-567. (c) Guisado O, Martinez S, Pastor J. Tetrahedron Lett 2002;43:7105-7109. (d) Shinada T, Umezawa T, Ando T, Kozuma H, Ohfune Y. Tetrahedron Lett 2006;47:1945-1947.

11. The configuration of the hemiaminal stereocenters was elucidated by $2 \mathrm{D}$ NMR experiments (see the Supporting Information).

12. The inability to separate the hemiaminal epimers of this product and later intermediates likely results from ready interconversion of the diastereomers on $\mathrm{SiO}_{2}$ and in protic solvents.

13. The simultaneous removal of the TBS ether is undoubtedly facilitated by the hemiaminal hydroxyl group, because desilylation does not occur in cyclizations of related substrates in which $\mathrm{C} 21$ is at the carbonyl oxidation state. 
14. Commercial $m$-chloroperoxybenzoic acid was purified by washing a $\mathrm{CH}_{2} \mathrm{Cl}_{2}$ solution of the peroxy acid with saturated aqueous $\mathrm{NaHCO}_{3}$ solution, drying the organic phase over $\mathrm{Na}_{2} \mathrm{SO}_{4}$, and carefully concentrating the dried solution in vacuo.

15. Among the publications on palau' amine and related structures, a H11/H12 NOE correlation was only mentioned for konbu'acidin A and tetrabromostyloguanidine (Refs. $2 \mathrm{~d}$ and ${ }^{4 \mathrm{c}}$ ).

16. Interproton distances were obtained from NOESY spectra with different mixing times $(100,150$, and $200 \mathrm{~ms}$ ). Intensity data from volume integration of NOESY crosspeaks were calibrated using the geminal proton pair at C13 (178 pm). Each NOESY spectrum was analyzed separately (linear approximation, verified by a linear relationship between volume integrals for different mixing times).

17. In all cases conformational searches were carried out to determine global minima. Only minima lacking intramolecular H-bonds were considered for calculations using Spartan 04. These results are given in the Supporting Information.

18. General experimental details are provided in the Supporting Information.

19. Hemiaminal diastereoisomers $\mathbf{3}$ and $\mathbf{4}$ interconvert at room temperature in $\mathrm{H}_{2} \mathrm{O}$ and therefore could not be obtained in diastereomerically pure form (i.e., diastereoisomer $\mathbf{3}$ could only be enriched to ca. $\left.90 \%\left({ }^{1} \mathrm{H}-\mathrm{NMR}\right)\right)$. 


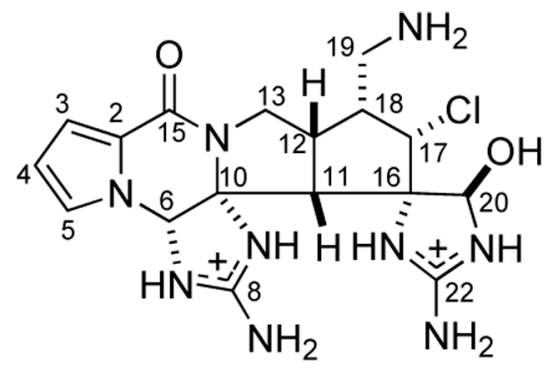

1

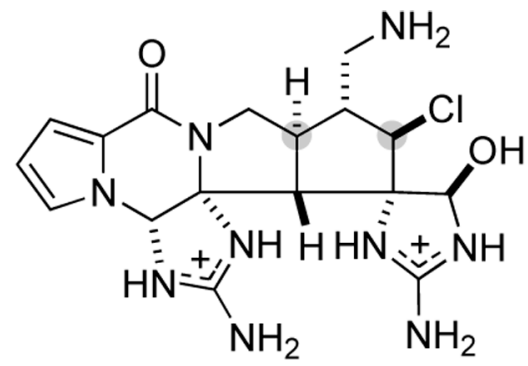

2

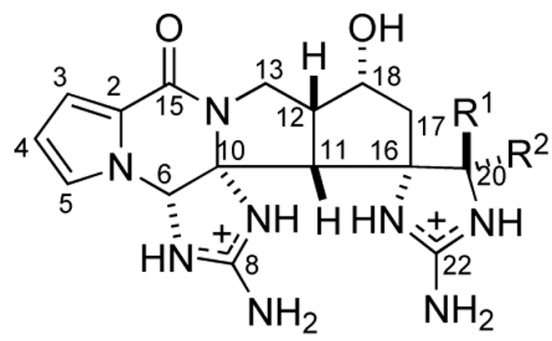

$3 \mathrm{R}^{1}=\mathrm{OH}, \mathrm{R}^{2}=\mathrm{H}$

$4 \mathrm{R}^{1}=\mathrm{H}, \mathrm{R}^{2}=\mathrm{OH}$

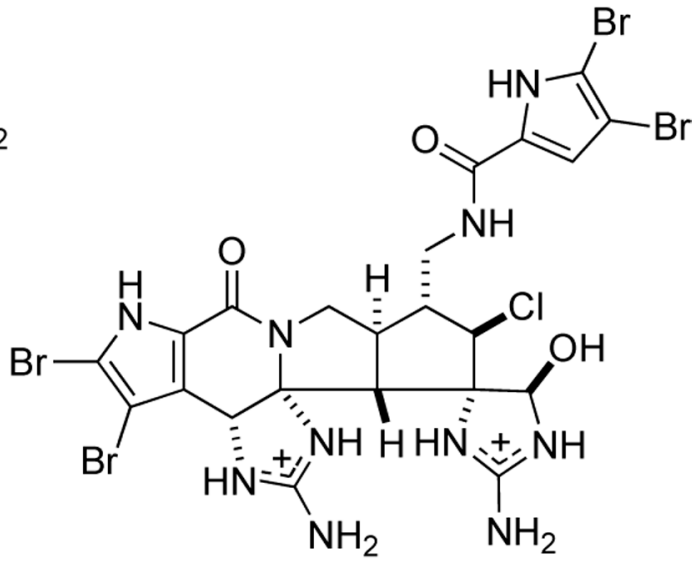

5

Figure 1.

Originally proposed structure of palau'amine (1), revised structure of palau'amine (2), synthetic derivatives $\mathbf{3}$ and $\mathbf{4}$, and structure of tetrabromostyloguanidine (5). Stereogenic centers with revised relative configurations have been highlighted with gray circles. 


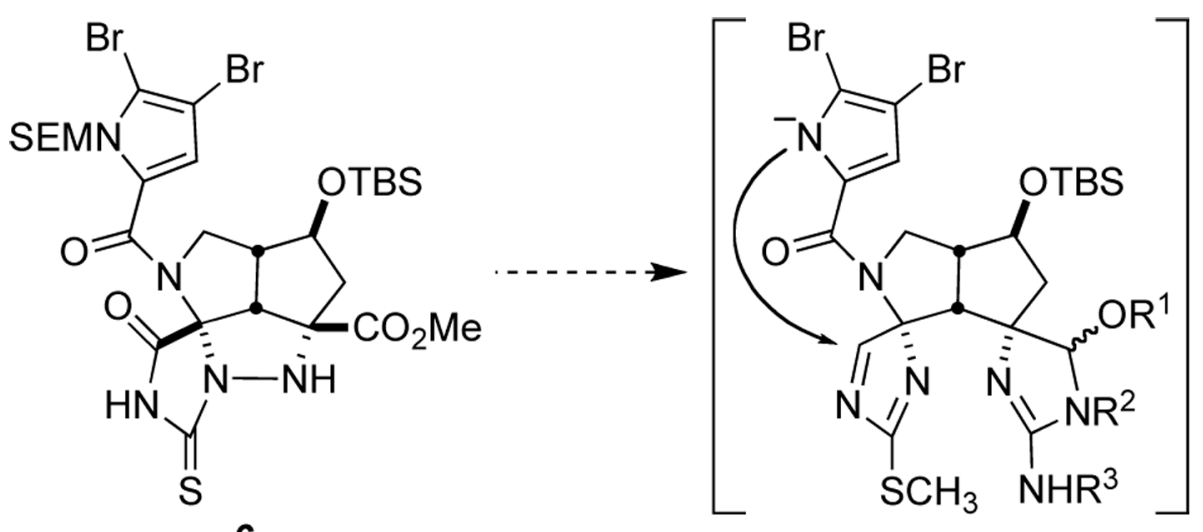

6

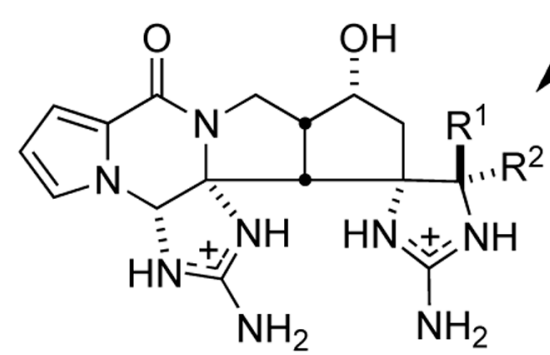

$3 \mathrm{R}^{1}=\mathrm{OH}, \mathrm{R}^{2}=\mathrm{H}$

$4 \mathrm{R}^{1}=\mathrm{H}, \mathrm{R}^{2}=\mathrm{OH}$

Scheme 1.

Plan for the conversion of intermediate $\mathbf{6}$ to palau'amine derivatives 3 and $\mathbf{4}$. 


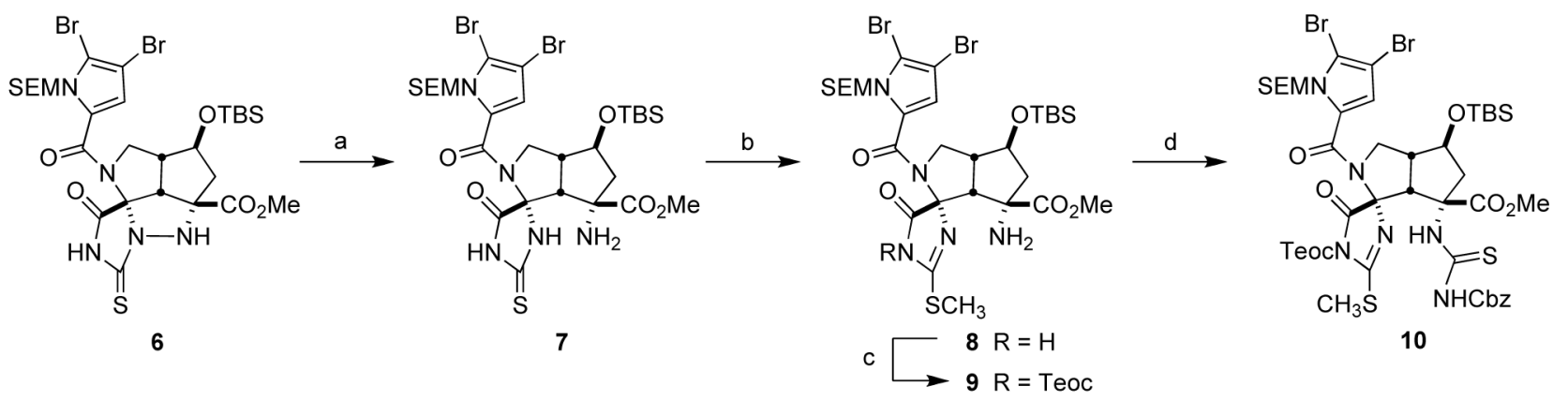

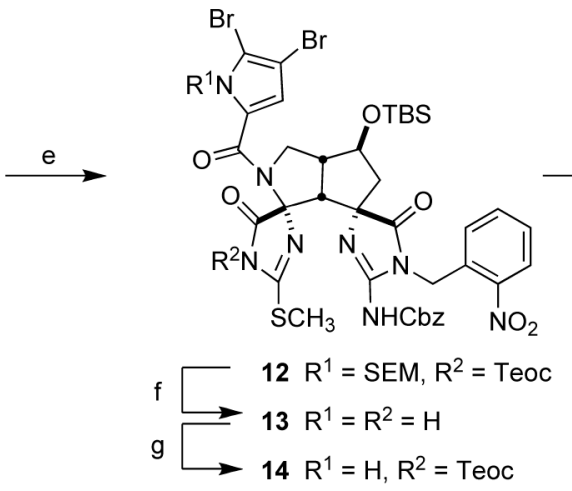

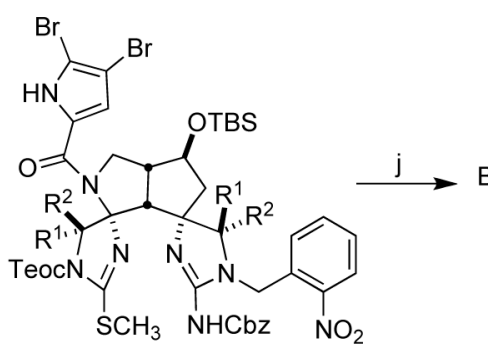

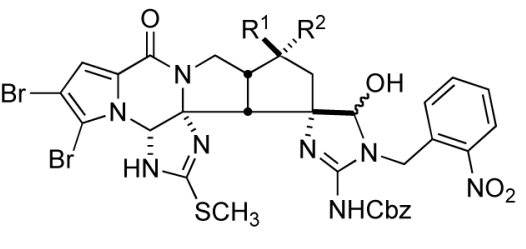

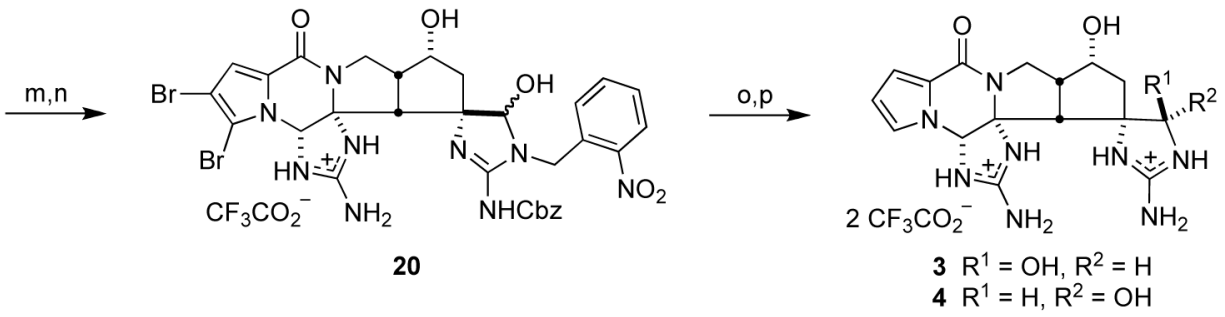

Scheme 2. Conversion of intermediate 6 into diastereomeric palau'amine derivatives 3 and 4.a a(a) $\mathrm{SmI}_{2}, \mathrm{THF} / \mathrm{MeOH}, 23{ }^{\circ} \mathrm{C}, 15 \mathrm{~min}, 79 \%$; (b) $\mathrm{MeI}, i-\mathrm{PrEt}_{2} \mathrm{~N}, \mathrm{DMAP}, \mathrm{CH}_{2} \mathrm{Cl}_{2}, 23{ }^{\circ} \mathrm{C}, 2 \mathrm{~h}$, 96\%; (c) Teoc-Cl, $i$ - $\mathrm{PrEt}_{2} \mathrm{~N}, \mathrm{CH}_{2} \mathrm{Cl}_{2}, 23{ }^{\circ} \mathrm{C}, 30 \mathrm{~min}$, quant.; (d) benzyloxycarbonyl isothiocyanate (11), $\mathrm{CH}_{2} \mathrm{Cl}_{2}, 40{ }^{\circ} \mathrm{C}, 1.5 \mathrm{~h}, 92 \%$; (e) EDCI, 2-nitrobenzylamine hydrochloride, $i$ - $\mathrm{PrEt}_{2} \mathrm{~N}, \mathrm{CH}_{2} \mathrm{Cl}_{2}, 40{ }^{\circ} \mathrm{C}, 2.5 \mathrm{~h}, 93 \%$; (f) $\mathrm{TFA}, \mathrm{CH}_{2} \mathrm{Cl}_{2}, 23{ }^{\circ} \mathrm{C}, 1 \mathrm{~h}$, then sat. aq. $\mathrm{Na}_{2} \mathrm{CO}_{3}, 94 \%$; (g) Teoc-Cl, $i$ - $\mathrm{PrEt}_{2} \mathrm{~N}, \mathrm{CH}_{2} \mathrm{Cl}_{2}, 23{ }^{\circ} \mathrm{C}, 30 \mathrm{~min}, 90 \%$; (h) $\mathrm{NaBH}_{4}, \mathrm{MeOH} / \mathrm{THF}(2: 1), 0{ }^{\circ} \mathrm{C}, 40$ min; (i) $\mathrm{Ac}_{2} \mathrm{O}$, pyridine, DMAP, $\mathrm{CH}_{2} \mathrm{Cl}_{2}, 23{ }^{\circ} \mathrm{C}, 4 \mathrm{~h}, 51 \%$ (15), 29\% (16) (2 steps); (j) TBAF, THF, $23{ }^{\circ} \mathrm{C}, 8 \mathrm{~min}, 95 \%$; (k) IBX, DMSO, $23{ }^{\circ} \mathrm{C}, 4 \mathrm{~h}, 96 \%$; (l) $\mathrm{NaBH}_{4}, \mathrm{MeOH}, 0{ }^{\circ} \mathrm{C}, 30 \mathrm{~min}$, 94\%; (m) $m$-CPBA, $\mathrm{CH}_{2} \mathrm{Cl}_{2}, 0 \rightarrow 23{ }^{\circ} \mathrm{C}, 40 \mathrm{~min}$; (n) $\mathrm{NH}_{3}, \mathrm{CH}_{2} \mathrm{Cl}_{2},-78 \rightarrow 23{ }^{\circ} \mathrm{C}, 14 \mathrm{~h}, 79 \%$ (2 steps); (o) hv, dioxane, $23{ }^{\circ} \mathrm{C}, 2.5 \mathrm{~h}$; (p) $\mathrm{H}_{2}, \mathrm{Pd} / \mathrm{C}$, dioxane $/ \mathrm{H}_{2} \mathrm{O}(0.1 \%$ TFA), $43 \%$ (3), $22 \%$ (4) (2 steps). DMAP = N,N-dimethylaminopyridine, Teoc- $\mathrm{Cl}=2$-trimethylsilylethyl chloroformate, EDCI = 1-(3-dimethylaminopropyl)-3-ethylcarbodiimide hydrochloride, TFA $=$ trifluoroacetic acid, TBAF $=\operatorname{tetra}(n$-butyl)ammonium fluoride, IBX $=o$-iodoxybenzoic acid, $m$-CPBA $=m$-chloroperoxybenzoic acid. 


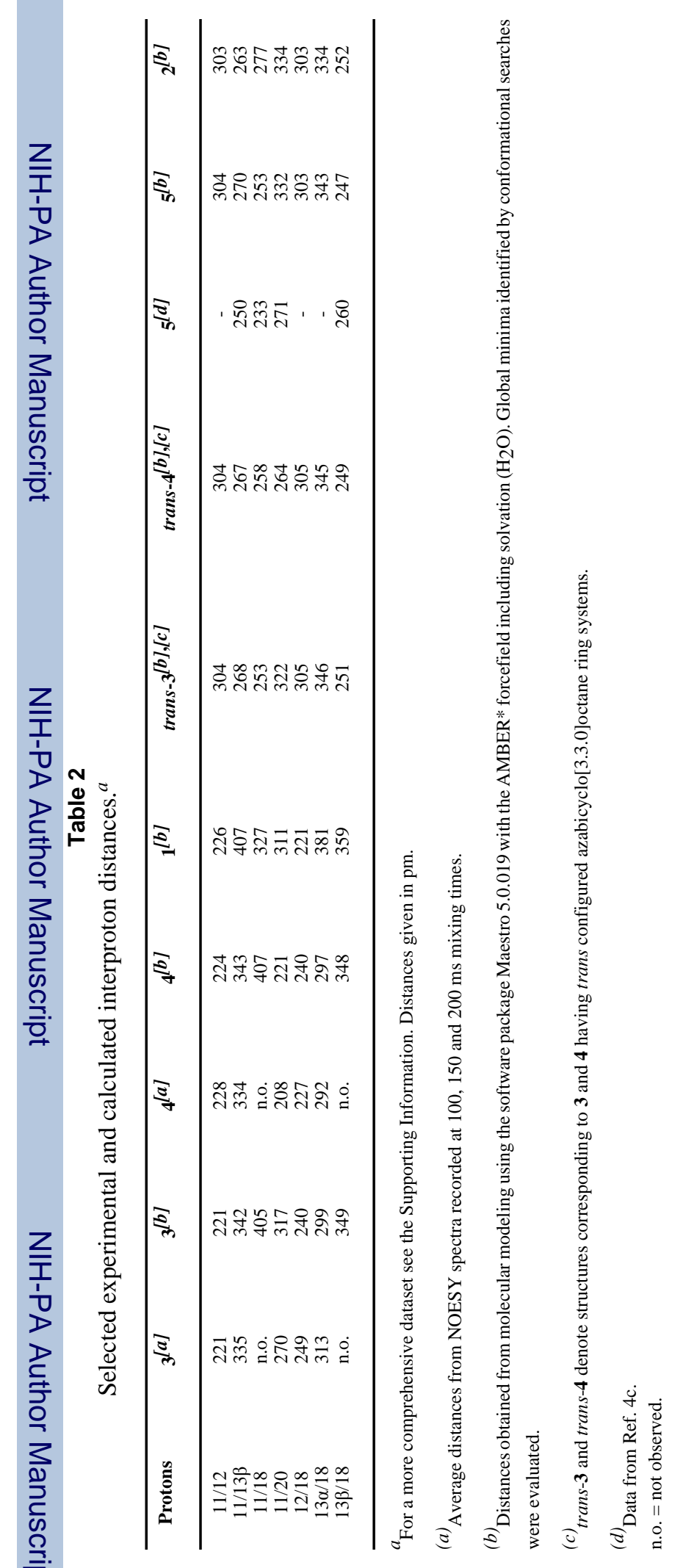

